\title{
Costs Associated with Productivity Loss Among U.S. Patients Newly Diagnosed with Multiple Myeloma Receiving Oral Versus Injectable Chemotherapy
}

\author{
David Merola, PharmD; Candice Yong, PhD; Stephen J. Noga, MD, PhD; \\ and Kenneth M. Shermock, PharmD, PhD
}

\begin{abstract}
BACKGROUND: The use of novel drug agents in the treatment of multiple myeloma (MM) has been associated with improved therapeutic outcomes and survival; however, MM continues to pose a significant economic burden on patients and health care systems. Evaluating economic implications of therapies can provide key points of distinctions between available treatment options. Patients with MM may experience productivity loss, including lost days from work or inability to work due to MM symptoms or to undergoing treatment. Although direct costs of illness have been well described in the literature, indirect costs associated with MM are understudied.
\end{abstract}

OBJECTIVE: To compare the extent of disability benefit use and resultant workplace productivity loss among U.S. adult patients with newly diagnosed MM who received oral versus injectable MM therapy.

METHODS: A retrospective cohort study was conducted using the Truven Health Analytics MarketScan Commercial Claims and Encounters, Medicare Supplemental Coordination of Benefits, and Health and Productivity Management databases (2008-2015). Workplace absenteeism, as measured by disability benefit use, was evaluated 1 year before and 1 year after first MM diagnosis. Patients receiving only oral chemotherapy were compared with those who received injectable therapy. Absenteeism days and associated costs were compared among study groups using multivariable zero-inflated Poisson regression.

RESULTS: The final study cohort included 299 patients with newly diagnosed MM, of whom 73 received oral therapy only and 226 received injectable therapy. Treatment type was a significant predictor of disability benefit use. Patients who received injectable therapy missed an average of 110 work days in the 1 year after diagnosis, compared with 87 for patients receiving only oral therapy (difference of 23 days, $95 \% \mathrm{Cl}=19-26$, $P<0.001$ ). Treatment type was also a significant predictor of costs associated with lost productivity. Patients who received injectable therapy experienced productivity loss valued at $\$ 18,315$, compared with patients who only received oral drug therapy $(\$ 14,429)$. The difference between these estimates was statistically significant $(\$ 3,886,95 \% \mathrm{Cl}=\$ 3,540-\$ 4,231$, $P<0.001)$.

CONCLUSIONS: Patients newly diagnosed with MM face significant losses in productivity. Patients receiving injectable MM therapy use significantly more disability benefits and incur higher productivity costs, compared with those receiving oral MM therapy. Further studies elucidating the nature of the differences between injectable and noninjectable chemotherapy users are needed.

J Manag Care Spec Pharm. 2018;24(10):1019-26

Copyright $\odot 2018$, Academy of Managed Care Pharmacy. All rights reserved.

\section{What is already known about this subject}

Cancer as a whole may be one of the costliest health conditions for employers and patients.

Multiple myeloma poses a significant economic burden on patients and the health care system.

Direct costs related to treatment and medical care of myeloma have been well described in the literature; however, indirect costs are understudied.

\section{What this study adds}

This study compared the extent of workplace productivity loss in patients newly diagnosed with multiple myeloma receiving oral versus injectable chemotherapy.

In the year following initial diagnosis with multiple myeloma, patients experience significant productivity loss, particularly those receiving injectable chemotherapy.

$\mathrm{M}$ ultiple myeloma (MM) is a hematologic malignancy that arises from plasma cells and is the 14th most common type of cancer in the United States. ${ }^{1}$ Treatment of MM has markedly improved in recent years with the introduction of novel agents, which possess immunomodulatory, antiangiogenesis, and antitumor properties. ${ }^{2}$ The use of these agents has been associated with improved therapeutic outcomes and survival rates, which are likely to continue improving as optimal therapeutic regimens become established and novel agents continue to emerge in the marketplace..$^{3-5}$

Despite advancements in treatment, MM poses a significant economic burden on patients and health care systems. ${ }^{6}$ Among several domains of patients' livelihood affected by the illness, employment and disability have been described to be particularly affected in recent literature. ${ }^{7}$ Cancer as a whole is among the costliest health conditions, with a projected cost of $\$ 173$ billion in the year 2020. ${ }^{8}$ Annual productivity costs associated with malignancies have been estimated to be approximately $\$ 1,601$ per patient in those at high risk for health conditions. ${ }^{9}$

Understanding the scope of financial burden due to disease is important to multiple health care stakeholders. Direct costs related to treatment and medical care of MM 


\section{Costs Associated with Productivity Loss Among U.S. Patients Newly Diagnosed}

with Multiple Myeloma Receiving Oral Versus Injectable Chemotherapy

have been well described. ${ }^{10-14}$ However, indirect costs associated with this particular cancer are understudied. ${ }^{15}$ The extent of productivity loss may vary across treatment modalities: a study by Petrucci et al. (2013) showed that the highest and lowest work-related, annual productivity costs per patient were reported by those who underwent autologous stem cell transplant (ASCT; $€ 9,538 \pm € 17,612$, equivalent to $\$ 7,963 \pm \$ 14,700$ in 2015 U.S. dollars) and asymptomatic patients (€22 $€ 95$, equivalent to $\$ 18.36 \pm \$ 79.29$ in 2015 U.S. dollars), equivalent to $16.1 \%$ and $2.3 \%$ of the total cost of illness, respectively. ${ }^{16}$ As well, patients receiving intravenous or subcutaneous therapies may experience additional treatment burden and productivity loss due to the frequent trips to the clinic for treatment administration. ${ }^{17,18}$

Losses in productivity due to complications and complexity of parenteral chemotherapy administration are relevant to patient preference and treatment satisfaction, which are important considerations in determining the value of particular treatment modalities. Recent literature suggests that the mode of drug administration is an important determinant of patient preference. A study by Simchowitz et al. (2010) concluded that an all-oral drug regimen was preferred among patients with relapsed/remitting MM and that drug administration was the most important factor in determining preference. ${ }^{19}$ In a small cross-sectional study of newly diagnosed MM patients, decreased economic burden and activity impairment was observed among users of oral versus injectable MM therapy. ${ }^{20}$ Workplace productivity loss is becoming an increasingly important outcome, as older adults are choosing to stay in the workforce longer. ${ }^{21}$ Furthermore, treatment options that enable patients to maintain greater workplace productivity can help defray direct costs of illness.

The purpose of this study was to examine the workplace productivity loss (measured by work absenteeism, short-term disability, and long-term disability days) among U.S. adult patients with an initial diagnosis of MM (IDMM) and estimate the resultant indirect costs due to productivity loss in these patients. These outcomes are compared among subjects who received oral versus injectable anticancer therapy in a retrospective cohort analysis. We hypothesized a greater indirect cost of illness posed by injectable versus oral chemotherapy agents.

\section{Methods}

\section{Data Source}

Analyses were conducted using the Truven Health Analytics MarketScan Commercial Claims and Encounters (CCAE) with Medicare Supplemental Coordination of Benefits and Health and Productivity Management (HPM) databases. These longitudinal datasets contain commercial claims from more than 100 million individual patients, including active employees, retirees, dependents of enrollees, and Medicare beneficiaries. ${ }^{22}$ Data elements include detailed information on prescription drug and medical claims, as well as absenteeism and disability benefit utilization. Collectively, these data elements enable estimation of indirect costs among patients receiving various treatments. All observations were deidentified and validated by Truven Health Analytics to ensure completeness, accuracy, and compliance with the Health Insurance Portability and Accountability Act (HIPAA) of 1996. Consequently, approval of this research by an institutional review board was not mandated.

\section{Sample Selection}

Subjects aged at least 18 years with an IDMM between January 1 , 2008, and December 31, 2014, were included in our study. MM diagnosis was identified using International Classification of Diseases, Ninth Revision, Clinical Modification (ICD-9-CM) codes 203.00, 203.01, 203.02. The date of the first claim that contained 1 of these diagnosis codes was considered the index date. ${ }^{23}$

To enhance the specificity of selecting patients with MM, only subjects with at least 1 MM diagnosis code appearing in any inpatient claim or at least $2 \mathrm{MM}$ diagnosis codes that appeared in outpatient claims and were 60-365 days apart were included. Also, subjects must have been continuously enrolled in a plan that included medical and disability benefits for 12 months before and after the index date to be included. Any evidence of another primary cancer (ICD-9-CM codes 140.xx195.xx, 199.xx-202.xx and 204.0x-209.xx) or metastatic disease (ICD-9-CM codes 196.xx-198.xx) before the index date warranted exclusion.

Once ascertained using these criteria, the MM study cohort was stratified according to 2 treatment types-recipients of oral chemotherapy and recipients of injectable chemotherapy only. The injectable chemotherapy stratum was selected on the basis of having at least 1 outpatient drug claim indicating a National Drug Code (NDC) number, Healthcare Common Procedure Coding System (HCPCS) code, or Current Procedural Terminology, 4th Edition (CPT-4), code corresponding to an injectable chemotherapy agent used in the treatment of MM during the study period. Consequently, this stratum contained subjects who used injectable chemotherapy, with or without oral chemotherapy agents.

The oral chemotherapy stratum was selected similarly, using NDC numbers and HCPCS codes corresponding to oral agents, but had no claims indicating injectable chemotherapy. Oral and/or injectable dosage forms of the following MM-specific chemotherapy drugs were included in our analysis: cyclophosphamide, melphalan, vincristine sulfate, doxorubicin hydrochloride, interferon alfa- $2 \mathrm{~b}$, lenalidomide, pomalidomide, thalidomide, bortezomib, carfilzomib, ixazomib citrate, daratumumab, elotuzumab, panobinostat, bendamustine, vorinostat, and dexamethasone. HCPCS/CPT-4 codes and NDC numbers used to identify treatment type are shown in Appendix A and Appendix B, respectively (available in online article). 


\section{Variables}

Baseline descriptive characteristics were described for subjects in each stratum using the following variables: age; gender; plan type (health maintenance organization [HMO], pointof-service [POS], preferred provider organization [PPO], and other); employee status (i.e., full time, part time, and other); industry; and geographic region. Additionally, comorbidity burden before each subject's index date was measured using the Charlson Comorbidity Index (CCI) using ICD-9-CM diagnosis codes contained in outpatient and inpatient claims. ${ }^{24,25}$

Productivity loss was evaluated using several key variables found within workplace absenteeism (WAB), short-term disability (STD), and long-term disability (LTD) claim files. A claim qualified for (a) STD, if it was for an extended period of absence, excluding weekend days, due to a particular diagnosis and was typically capped by employers at 6 months; (b) LTD, if it was for an extended period of absence, excluding weekend days, due to a particular diagnosis and typically occurred after STD benefits had ended; and (c) WAB, if it was for any days absent from work (e.g., sick, leave, recreational, other, or Family Medical Leave Act), except for those due to disability. Two variables-corresponding to the first day of missed work and first day of return to work for each patient claim-were used to obtain the number of absenteeism days for each patient. Workplace productivity loss (WPL), an aggregate of absenteeism days, was calculated using claims for WAB, STD, and LTD benefits.

Absenteeism days were captured at the month-level for each benefit type. Consequently, if patients used 2 benefits in a given month, it was not possible to discern exactly when each benefit was used within that month. When calculating WPL in these instances, absenteeism days linked to the most frequently used benefit were included in the measure; absenteeism days associated with any other benefit in that month were disregarded. For example, if a patient used 20 days of STD and 5 days of WAB in the same month, 20 days were counted for that entire month. This was done to yield a conservative measure of missed workdays (by avoiding the potential to doublecount absenteeism days).

From the disease outcomes perspective, there is no evidence indicating injectable therapies (vs. oral therapies) have better outcomes beyond a 1-year period. Consequently, productivity loss is most likely better reflected in the short term following initial diagnosis. For this reason, outcomes were analyzed at the patient-month level throughout a 12-month baseline and 12-month follow-up period.

\section{Estimated Costs of Productivity Loss}

The financial burden of productivity loss was calculated in 2015 U.S. dollars for each patient-month by multiplying the number of absenteeism days (as indicated in the aggregate WPL measure) by the average daily wage for all occupations,

\begin{tabular}{|c|c|}
\hline TABLE & $\begin{array}{l}\text { tipliers Used to Calculate Cost } \\
\text { den of Workplace Productivity Loss }\end{array}$ \\
\hline WAB & $\begin{array}{l}\text { (Absenteeism days from aggregate WPL } \\
\text { measure }) \times\left(1.3^{\mathrm{a}}\right) \times\left(23.23^{\mathrm{b}}\right) \times\left(8^{\mathrm{c}}\right)\end{array}$ \\
\hline STD and LTD & $\begin{array}{l}\text { (Absenteeism days from aggregate WPL } \\
\text { measure }) \times\left(1.3^{\mathrm{a}}\right) \times(23.23 \mathrm{~b}) \times(8 \mathrm{c}) \times\left(0.6^{\mathrm{d}}\right)\end{array}$ \\
\hline \multicolumn{2}{|c|}{ 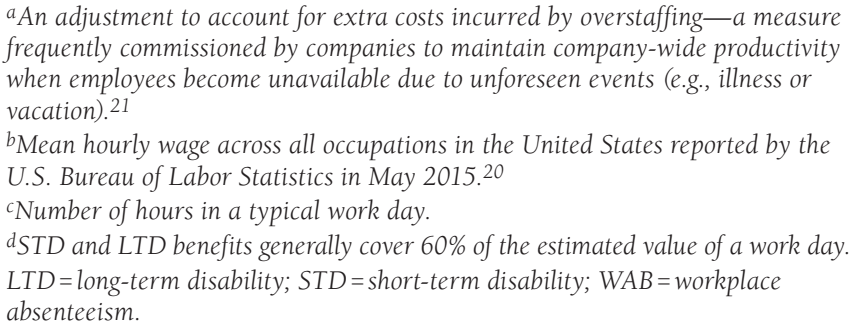 } \\
\hline
\end{tabular}

as reported by the U.S. Bureau of Labor Statistics. ${ }^{26}$ In addition, multipliers corresponding to each benefit type, derived from a study conducted by Goetzel et al. (1999), were applied to account for extra costs incurred to maintain productivity during employee absenteeism (Table 1). ${ }^{27}$ Data indicating the number of absenteeism days for each benefit were captured at the month-level. As explained above, when 2 benefits were used in a given month, the most frequently used benefit (and corresponding multiplier) was employed in our calculation, and any other benefit and its corresponding multiplier were disregarded. Monthly costs were calculated in the manner described here for each patient and subsequently summated for the 12 months following an IDMM diagnosis. The resultant figures were used in our statistical analyses to estimate differences in costs associated with productivity loss between study groups.

\section{Statistical Analyses}

The study cohort's baseline characteristics, categorical variables (e.g., gender) were described using proportions, and continuous variables (e.g., age) were described using the mean, median, and standard deviation. Student's t-tests and chi-square tests were used to evaluate differences in continuous and categorical variables between different study cohort groups, respectively. The rank sum test was used to evaluate differences in the median age across study groups.

Days of lost productivity and their associated economic value were compared using multivariable zero-inflated Poisson regression. ${ }^{28}$ This model offered 2 benefits that were very important to our analysis. First, it explicitly accounted for the presence of large numbers of "zeros." Many patients actually did not use absenteeism days. The model accounted for this from a statistical perspective. Second, it allowed us to adjust for potential confounding variables, as one would do in a multivariable least squares regression. The following variables were used as covariates in the models: age, index year, gender, CCI, and plan type. 


\section{Costs Associated with Productivity Loss Among U.S. Patients Newly Diagnosed with Multiple Myeloma Receiving Oral Versus Injectable Chemotherapy}

\section{FIGURE 1 Application of Exclusion Criteria to Assemble Final Study Cohort}

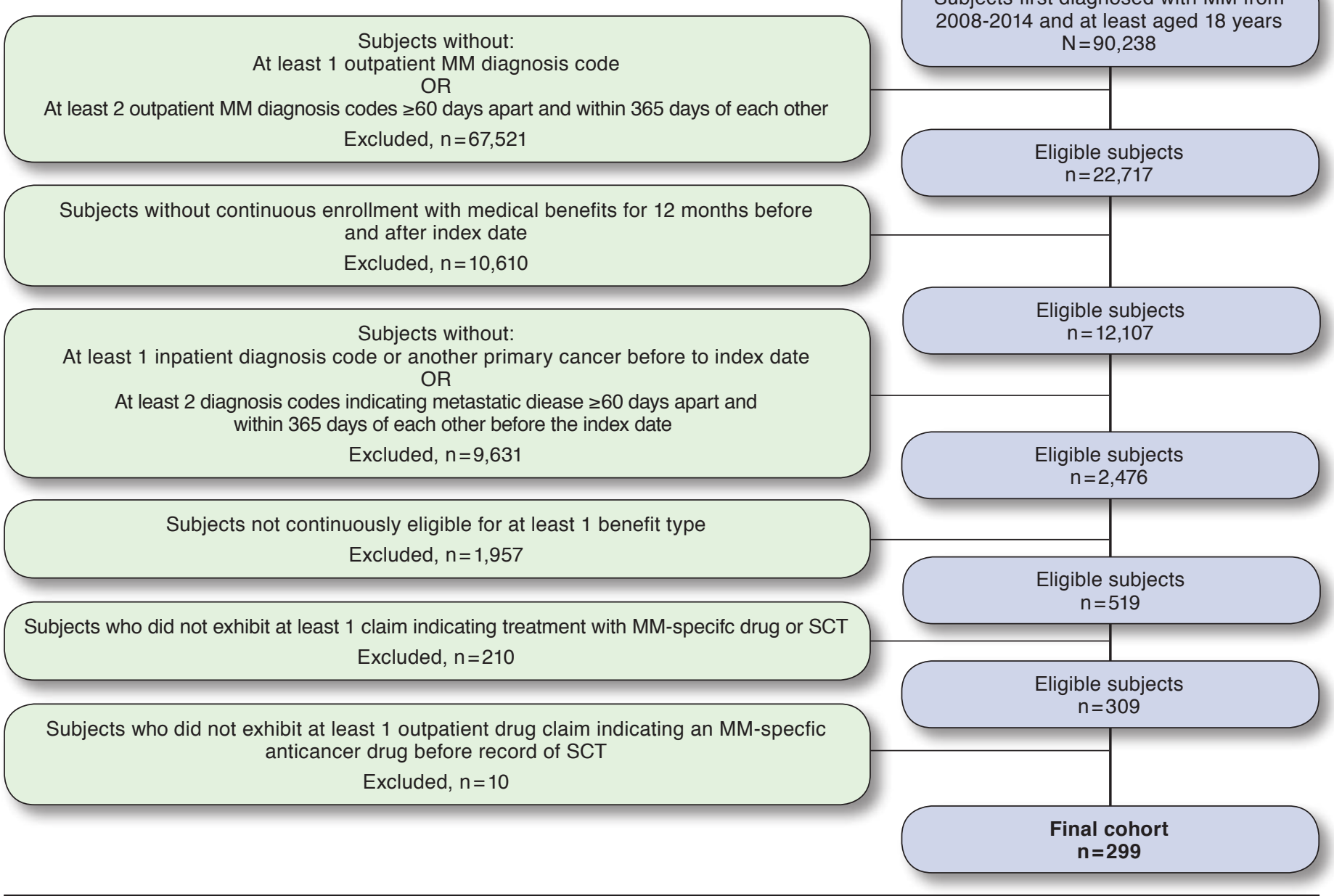

MM = multiple myeloma; SCT = stem-cell transplant

All data management and analyses were carried out using StataMP, version 14.1 (StataCorp, College Station, TX).

\section{Results}

The attrition to the study cohort as each exclusion criterion was applied can be seen in Figure 1. A total of 90,238 individuals were aged at least 18 years and received an IDMM from 2008 to 2014 in our dataset. Of these, 299 patients met all selection criteria and were included in the final analytic cohort. In our cohort, patients who used oral chemotherapy only $(n=73)$ had a mean age of 52 years and were mostly male (66\%). Similarly, patients who used injectable chemotherapy $(n=226)$ had a mean age of 51 years and were also mostly male (71\%). Baseline characteristics of each study group are depicted in Table 2.

Of the overall cohort, $32 \%(n=96)$ used some form of disability benefit before an IDMM, compared with 63\% ( $n=188)$ after diagnosis. In the prediagnosis period, the most frequently used benefit was WAB $(n=70)$, followed by STD $(n=30)$ and LTD $(n=1)$. Alternatively, in the postdiagnosis period, STD was the most frequently used benefit $(n=143)$, followed by WAB $(n=63)$ and $\operatorname{LTD}(n=24)$. Benefit use observed in each study group is summarized in Table 3 . The average number of disability days used over the entire cohort was 25 days (median $=0$ ) in the year before diagnosis and 105 days (median $=64)$ in the year after initial diagnosis $(P<0.001$ by t-test and rank sum test). Among patients who used any disability benefits, the median disability days used was 51 (mean $=78$ ) in the year before diagnosis and $154($ mean $=167)$ in the year after initial diagnosis $(P<0.001$, rank sum test).

In the adjusted comparison of the number of missed work days, treatment type was a significant predictor of the number of missed work days per patient in the year following an IDMM 


\section{Costs Associated with Productivity Loss Among U.S. Patients Newly Diagnosed with Multiple Myeloma Receiving Oral Versus Injectable Chemotherapy}

\begin{tabular}{|c|c|c|c|}
\hline & $\begin{array}{c}\text { Oral } \\
\text { Chemotherapy } \\
\text { Users }\end{array}$ & $\begin{array}{c}\text { Injectable } \\
\text { Chemotherapy } \\
\text { Users }\end{array}$ & $P$ Value $^{\mathrm{a}}$ \\
\hline Sample size (n) & 73 & 226 & \\
\hline \multicolumn{4}{|l|}{ Age at baseline, years } \\
\hline Mean & 52.0 & 51.4 & 0.579 \\
\hline Median & 52.0 & 53.0 & 0.929 \\
\hline SD & 5.4 & 7.2 & \\
\hline Age group, years, n (\%) & & & 0.153 \\
\hline $18-44$ & $7 \quad(9.6)$ & $40 \quad(17.7)$ & \\
\hline $45-54$ & $38 \quad(52.1)$ & $94 \quad(41.6)$ & \\
\hline $55-64$ & $28 \quad(38.4)$ & $92 \quad(40.7)$ & \\
\hline Sex, n (\%) & & & 0.374 \\
\hline Male & $48 \quad(65.8)$ & $161 \quad(71.4)$ & \\
\hline Female & $25 \quad(34.3)$ & $65 \quad(28.6)$ & \\
\hline Index year, n (\%) & & & 0.005 \\
\hline 2009 & $13 \quad(17.8)$ & $14 \quad(6.2)$ & \\
\hline 2010 & $11 \quad(15.1)$ & $28 \quad(12.4)$ & \\
\hline 2011 & $15 \quad(20.6)$ & $31 \quad(13.7)$ & \\
\hline 2012 & $13 \quad(17.8)$ & $46 \quad(20.4)$ & \\
\hline 2013 & $15 \quad(20.6)$ & $57 \quad(25.2)$ & \\
\hline 2014 & $6 \quad(8.2)$ & $50 \quad(22.1)$ & \\
\hline Region, n (\%) & & & 0.641 \\
\hline Northeast & $14 \quad(19.2)$ & $51 \quad(22.6)$ & \\
\hline North Central & $18 \quad(24.7)$ & $47 \quad(20.8)$ & \\
\hline South & $23 \quad(31.5)$ & $83 \quad(36.7)$ & \\
\hline West & $18 \quad(24.7)$ & $45 \quad(19.9)$ & \\
\hline Plan type, n (\%) & & & 0.092 \\
\hline $\mathrm{HMO}$ & $12 \quad(16.4)$ & $26 \quad(11.5)$ & \\
\hline POS & $2 \quad(2.7)$ & $24 \quad(10.6)$ & \\
\hline $\mathrm{PPO}$ & $48 \quad(65.8)$ & $130 \quad(57.5)$ & \\
\hline Other & $11 \quad(15.1)$ & $46 \quad(20.4)$ & \\
\hline CCI score, $\mathrm{n}(\%)$ & & & 0.171 \\
\hline 0 & $32 \quad(43.8)$ & $90 \quad(39.8)$ & \\
\hline 1 & $16 \quad(21.9)$ & $53 \quad(23.5)$ & \\
\hline 2 & (9.6) & $44 \quad(19.5)$ & \\
\hline$>3$ & $18 \quad(24.7)$ & $39 \quad(17.3)$ & \\
\hline
\end{tabular}

aT-test was used to evaluate mean age and rank sum for median age; chi-square test was used for remaining categorical variables.

$C C I=$ Charlson Comorbidity Index; $H M O=$ health maintenance organization; $P O S=$ point-of-service $P P O=$ preferred provider organization .

diagnosis. Patients who received injectable therapy missed an average of 110 work days. In contrast, patients receiving oral therapy missed an average of 87 work days. This difference was statistically significant $(22.5$ days, $95 \% \mathrm{CI}=19-26, P<0.001)$. In the same multivariable model, older age was associated with fewer missed work days. Patients aged 45 years or older experienced an average of 26 fewer missed work days compared with individuals who were younger than 45 years $(95 \% \mathrm{CI}=-31-21$ days, $P<0.001)$. Additionally, patients with a CCI score greater than zero experienced on average 6.8 additional missed work days compared with patients whose CCI score was zero (95\% $\mathrm{CI}=4.3-9.4, P<0.001)$.
Treatment type was also a significant predictor of costs associated with lost productivity. Patients who received injectable therapy experienced productivity loss valued at $\$ 18,500$, compared with patients who only received oral drug therapy $(\$ 14,605)$. This difference was statistically significant $(\$ 3,894$, 95\% CI $=\$ 3,547-\$ 4,241, P<0.001)$. Patients aged between 45 and 54 years experienced $\$ 2,302$ less costs associated with productivity loss, on average (95\% CI $=-\$ 2,511-\$ 2,094$, $P<0.001)$ compared with patients aged less than 45 years. Patients aged 55 years and older experienced $\$ 2,580$ less costs associated with productivity loss $(95 \% \mathrm{CI}=-\$ 2,811-\$ 2,347$, $P<0.001)$ compared with patients aged less than 45 years. Additionally, patients with a CCI score greater than zero experienced an average of $\$ 1,515$ greater costs associated with productivity loss compared with patients whose CCI score was zero $(95 \% \mathrm{CI}=\$ 1,377-\$ 1,653, P<0.001)$.

\section{Discussion}

Loss of productivity is a significant contributor of financial hardship in patients with cancer. It has been estimated that up to $62 \%$ of cancer survivors report accruing debt due to their oncologic therapies, with average losses of productivity in the range of $\$ 380$ to $\$ 8,236 .{ }^{28}$ There is tremendous variability in the measurement of productivity loss in the published literature, including missed work days, limitations in housework or school, lost income, and time spent in bed. ${ }^{29-31}$ Here, we present the first study to valuate productivity loss as measured by disability benefit use among MM patients receiving injectable versus oral chemotherapy. Although overall survival in patients with MM has significantly increased in the past decade due to improved treatments, this study demonstrates an increasing financial burden posed by MM therapies. Our findings highlight the importance of considering indirect costs alongside efficacy, safety, and direct costs during the treatment decisionmaking process.

The overall study cohort exhibited a use of 87-110 absenteeism days, on average, in the year following initial MM diagnosis, with higher use of absenteeism days for patients on injectable versus oral therapy. Average costs associated with these days ranged from approximately $\$ 14,500$ to $\$ 18,000$, depending on treatment type, with higher costs associated with patients on injectable therapy versus oral therapy. These results compare with a similar study conducted on breast cancer patients (60 absenteeism days valuated at \$4,900) and patients with non-Hodgkin lymphoma (65 days valuated at $\$ 12,741){ }^{33,34}$ Productivity loss has also been evaluated with similar figures in patients with colorectal malignancies. ${ }^{35}$

Comparisons among these studies should be interpreted with caution, however, since there is significant variability in the methodologies used to evaluate productivity loss. For example, our monetary figures were adjusted to account for overstaffing, while analogous estimations by Yu et al. (2016) 
TABLE 3 Productivity Loss and Associated Costs of Multiple Myeloma Patients Receiving Treatment

\begin{tabular}{|c|c|c|c|c|c|}
\hline \multirow{2}{*}{ Benefit users before diagnosis, $\mathrm{n}(\%)$} & \multicolumn{2}{|c|}{$\begin{array}{l}\text { Oral Chemotherapy Users } \\
(\mathbf{n}=73)\end{array}$} & \multicolumn{2}{|c|}{$\begin{array}{c}\text { Injectable Chemotherapy } \\
\text { Users }(n=226)\end{array}$} & \multirow{2}{*}{$\begin{array}{c}\begin{array}{c}P \\
\text { Value }^{\mathrm{a}}\end{array} \\
0.707 \\
\end{array}$} \\
\hline & & & & & \\
\hline WAB & 18 & $(24.7)$ & 52 & $(23.0)$ & \\
\hline STD & 6 & $(8.2)$ & 24 & $(10.6)$ & \\
\hline LTD & 0 & $(0)$ & 1 & $(0.4)$ & \\
\hline Benefit users after diagnosis, $\mathrm{n}(\%)$ & & & & & 0.830 \\
\hline WAB & 17 & $(23.3)$ & 46 & $(20.4)$ & \\
\hline STD & 35 & $(48.0)$ & 108 & $(47.8)$ & \\
\hline LTD & 5 & $(6.9)$ & 19 & $(8.4)$ & \\
\hline Predicted number of missed work days in year after MM diagnosis, ${ }^{b}$ days (95\% CI) & 87.2 & .2-95.3) & 109.7 & $3-120.0)$ & $<0.001$ \\
\hline Predicted costs of missed work in year after MM diagnosis, ${ }^{b}$ USD (95\% CI) & $\$ 14,605(\$ 1$ & $2-\$ 15,900)$ & $\$ 18,500(\$ 1$ & $52-\$ 20,139)$ & $<0.001$ \\
\hline
\end{tabular}

were not. ${ }^{34}$ Regardless, our findings demonstrate that an initial diagnosis with MM is related to a significant increase in absenteeism days used in the subsequent 12 months.

Consideration of the other sources of economic burden imposed by MM in the context of our findings is instructive. Several studies that evaluated the direct expenses of various MM treatments found an average monthly cost ranging from $\$ 13,876$ to $\$ 47,417.36,37$ These investigations demonstrate that the direct costs of treatment from the payer perspective are similar in magnitude to our estimates of indirect costs from the patient perspective.

The indirect costs associated with workplace absenteeism are significant and contribute to the overall economic burden of MM. Furthermore, our results showed that patients who received injectable therapy experienced a greater increase in lost productivity compared with patients who received oral therapy.

\section{Limitations}

There are several limitations associated with our analyses. Importantly, there are very limited clinical data in the Truven CCAE database, which reduced our capacity to establish clinical causes and conditions that led to the observed choices of therapy and subsequent differences in productivity loss. For example, patients may have had to take time off work due to various reasons including disease-related symptoms, treatment-related toxicities, travel time to and from the clinic, and for treatment administration. Because we did not have access to this information, our analysis is silent on these and related phenomena. As demonstrated in a previous study, complications and side effects of chemotherapy, such as neutropenia, have been shown to explain differences in short-term disability use. ${ }^{38}$ Other potential explanatory factors that are not represented in the Truven database include the type of occupation, complexity of chemotherapy administration, and treatment response. Socioeconomic status was also unavailable in our dataset and may have influenced the measured outcomes. For instance, subjects with high socioeconomic status may have exhibited more confidence in taking time off work. To address this, our multivariable model was adjusted for health-plan type, which could have captured some aspect of this potential confounder.

Our small sample size was an additional limitation, especially with respect to the number of patients receiving oral chemotherapy $(n=73)$. Although our estimations reached statistical significance, larger sample sizes would likely allot more representative figures, as well as enable an exploration of the relative differences in outcomes of each chemotherapy agent. Furthermore, our study population was among working adults in the United States with disability benefits. These results, therefore, may not be generalizable to other populations.

The scope of our study was limited to the consideration of productivity-related losses. Although these losses are important to patients and employers, the scope is somewhat limited and falls short of a full cost-effectiveness analysis. The requisite data sources to accomplish such an analysis were unavailable to us. Nevertheless, we feel this current work is a valuable contribution.

\section{Conclusions}

Future studies are needed to elucidate the conditions that lead to greater productivity loss among injectable chemotherapy users. Data that permit a larger sample size, more clinical details, and greater follow-up times would be helpful in tracking treatment outcomes of MM therapies. A more comprehensive picture, in this regard, may empower patients and clinicians with strategies to reduce the overall economic burden imposed by MM and, in turn, promote greater quality of care. This study examined the productivity loss and associated costs in the year following a new diagnosis of MM. The greater productivity loss observed among patients treated with 


\section{Costs Associated with Productivity Loss Among U.S. Patients Newly Diagnosed with Multiple Myeloma Receiving Oral Versus Injectable Chemotherapy}

injectable therapy may continue to persist over a longer time horizon (e.g., 2 or 3 years after diagnosis) as patients increasingly receive long-term treatment.

An initial diagnosis with MM is associated with an increased use of disability benefits in the year following initial diagnosis. Injectable chemotherapy use appears related to a greater use of disability benefits than oral chemotherapy use in the setting of this particular cancer.

\section{Authors}

DAVID MEROLA, PharmD, Bernard J. Dunn School of Pharmacy, Shenandoah University, Winchester, Virginia. CANDICE YONG, PhD, and STEPHEN J. NOGA, MD, PhD, Millennium Pharmaceuticals, Cambridge, Massachusetts. KENNETH M. SHERMOCK, PharmD, PhD, Department of Pharmacy, The Johns Hopkins Hospital, Baltimore, Maryland.

AUTHOR CORRESPONDENCE: Kenneth M. Shermock, PharmD, $\mathrm{PhD}$, Center for Medication Quality and Outcomes, The Johns Hopkins Hospital, 600 N. Wolfe St., Carnegie 180, Baltimore, MD 21287. Tel.: 410.502.7674; E-mail: ken@jhmi.edu.

\section{DISCLOSURES}

This study was funded by Millennium Pharmaceuticals, a wholly owned subsidiary of Takeda Pharmaceutical Company. Yong and Noga are employees of Millennium Pharmaceuticals. Merola reports personal fees from Millennium Pharmaceuticals during the time of this study.

\section{REFERENCES}

1. National Institute of Health. Cancer stat facts: myeloma. November 2016. Available at: https://seer.cancer.gov/statfacts/html/mulmy.html. Accessed July 17, 2018

2. Nathwani N, Larsen JT, Kapoor P. Consolidation and maintenance therapies for newly diagnosed multiple myeloma in the era of novel agents. Curr Hematol Malig Rep. 2016;11(2):127-36.

3. Yong K, Delforge M, Driessen C, et al. Multiple myeloma: patient outcomes in real-world practice. Br J Haematol. 2016;175(2):252-64.

4. Durie BG, Hoering A, Abidi MH, et al. Bortezomib with lenalidomide and dexamethasone versus lenalidomide and dexamethasone alone in patients with newly diagnosed myeloma without intent for immediate autologous stem-cell transplant (SWOG S0777): a randomised, open-label, phase 3 trial. Lancet. 2017;389(10068):519-27.

5. Kumar SK, Dispenzieri A, Lacy MQ, et al. Continued improvement in survival in multiple myeloma: changes in early mortality and outcomes in older patients. Leukemia. 2014;28(5):1122-28

6. de Souza JA, Muffly L. The overlooked COST of multiple myeloma. Lancet Haematol. 2015;2(10):e394-95.

7. Goodwin JA, Coleman EA, Sullivan E, et al. Personal financial effects of multiple myeloma and its treatment. Cancer Nursing. 2014;36(4):301-08.

8. Mariotto AB, Yabroff KR, Shao Y, et al. Projections of the cost of cancer in the United States: 2010-2020. J Natl Cancer Inst. 2011;103(8):699.

9. Mitchell RJ, Bates P. Measuring health-related productivity loss. Popul Health Manag. 2011;14(2):93-98.
10. Zhou X, Xia J, Mao J, et al. Real-world outcome and healthcare costs of relapsed or refractory multiple myeloma: A retrospective analysis from the Chinese experience. Hematology. 2016;21(5):280-86.

11. Aguiar PM, Lima TM, Storpirtis S. Systematic review of the economic evaluations of novel therapeutic agents in multiple myeloma: what is the reporting quality? J Clin Pharm Ther. 2016;41(2):189-97.

12. Borg S, Nahi H, Hansson M, et al. Cost effectiveness of pomalidomide in patients with relapsed and refractory multiple myeloma in Sweden. Acta Oncol. 2016;55(5):554-60.

13. Chen W, Yang Y, Chen Y, et al. Cost-effectiveness of bortezomib for multiple myeloma: a systematic review. Clinicoecon Outcomes Res. 2016;8:137-51.

14. Jakubowiak AJ, Campioni M, Benedict Á, et al. Cost-effectiveness of adding carfilzomib to lenalidomide and dexamethasone in relapsed multiple myeloma from a U.S. perspective. J Med Econ. 2016;19(11):1061-74.

15. Kamal KM, Covvey JR, Dashputre A, et al. A systematic review of the effect of cancer treatment on work productivity of patients and caregivers. J Manag Care Spec Pharm. 2017;23(2):136-62. Available at: https://www.jmcp. org/doi/10.18553/jmcp.2017.23.2.136.

16. Petrucci MT, Calabrese E, Levi A, et al. Cost of illness in patients with multiple myeloma in Italy: the CoMiM study. Tumori. 2013;99(4):e193-202.

17. Kumar SK, Vij R, Noga SJ, et al. Treating multiple myeloma patients with oral therapies. Clin Lymphoma Myeloma Leuk. 2017;17(7):391-462.

18. Baz R, Lin HM, Hui A-M, et al. Development of a conceptual model to illustrate the impact of multiple myeloma and its treatment on health-related quality of life. Support Cancer Care. 2015;23(9):2789-2797

19. Simchowitz B, Shiman L, Spencer J, et al. Perceptions and experiences of patients receiving oral chemotherapy. Clin J Oncol Nurs. 2010;14:447-53.

20. Romanus D, DasMahapatra P, Hoole M, et al. Treatment satisfaction and burden of illness with oral vs injectable multiple myeloma therapy in patients with newly diagnosed disease (NDMM). Value Health. 2017;20(9):A454 [abstract]

21. Pew Research Center. More older Americans are working, and working more, than they used to. June 20, 2016. Available from: http://www.pewresearch.org/fact-tank/2016/06/20/more-older-americans-are-working-andworking-more-than-they-used-to/. Accessed July 17, 2018.

22. Truven Health Analytics. Health research data for the real world: the MarketScan databases. White paper. July 2011. Available from: http://truvenhealth.com/portals/0/assets/PH_11238_0612_TEMP_MarketScan_WP_ FINAL.pdf. Accessed July 17, 2018.

23. Princic N, Gregory C, Wilson T, et al. Development of an algorithm to identify patients with Multiple Myeloma using administrative claims data. Blood. 2015;126:4521

24. Quan H, Sundararajan V, Halfon P, et al. Coding algorithms for defining comorbidities in ICD-9-CM and ICD-10 administrative data. Med Care. 2005;43(11):1073-77.

25. Charlson ME, Pompei P, Ales KL, McKenzie CR. A new method of classifying prognostic comorbidity in longitudinal studies: development and validation. J Chron Dis. 1987;40(5):373-83.

26. U.S. Bureau of Labor Statistics. May 2015 national occupational employment and wage estimates. March 2016. Available at: https://www.bls.gov/ oes/2015/may/oes_nat.htm\#00-0000. Accessed July 17, 2018.

27. Goetzel RZ, Hawkins, K, Ozminkowski RJ, et al. The health and productivity cost burden of the "top 10" physical and mental health conditions affecting six large US employers in 1999. J Occup Environ Med. 2003;45(1):5-14.

28. Long JS, Freese J. Models for count outcomes. In: Regression Models for Categorical Dependent Variables Using Stata. 3rd ed. College Station, TX: Stata Press; 2014:481-560.

29. Altice CK, Banegas MP, Tucker-Seeley RD, Yabroff KR. Financial hardships experienced by cancer survivors. J Natl Cancer Inst. 2017;109(2):djw205. 


\section{Costs Associated with Productivity Loss Among U.S. Patients Newly Diagnosed with Multiple Myeloma Receiving Oral Versus Injectable Chemotherapy}

30. Dowling EC, Chawla N, Forsythe LP, et al. Lost productivity and burden of illness in cancer survivors with and without other chronic conditions. Cancer. 2013;119(18):3393-401

31. Chirikos TN, Russell-Jacobs A, Cantor AB. Indirect economic effects of longterm breast cancer survival. Cancer Pract. 2002;10(5):248-55.

32. Guy GP Jr, Ekwueme DU, Yabroff KR, et al. Economic burden of cancer survivorship among adults in the United States. J Clin Oncol. 2013;31(30):3749-57.

33. Meadows ES, Johnston SS, Cao Z, et al. Illness-associated productivity costs among women with employer-sponsored insurance and newly diagnosed breast cancer. J Occup Environ Med. 2010;52(4):415-20.

34. Yu JS, Hansen RN, Valderrama A, et al. Indirect costs and workplace productivity loss associated with non-Hodgkin lymphoma. Leuk Lymphoma. 2016:57(11):2636-43
35. Yabroff KR, Warren JL, Knopf K, et al. Estimating patient time costs associated with colorectal cancer care. Med Care. 2005;43(7):640-48.

36. MacEwan JP, Batt K, Yin W, et al. Economic burden of multiple myeloma among patients in successive lines of therapy in the United States. Leuk Lymphoma. 2017;13:1-9.

37. Arikian SR, Milentijevic D, Binder G, et al. Patterns of total cost and economic consequences of progression for patients with newly diagnosed multiple myeloma. Curr Med Res Opin. 2015;31(6):1105-15.

38. Song X, Fowler R, Ruiz K, et al. Impact of neutropenic complications on short-term disability in patients with cancer receiving chemotherapy. J Med Econ. 2009;12(2):154-63 
Costs Associated with Productivity Loss Among U.S. Patients Newly Diagnosed

with Multiple Myeloma Receiving Oral Versus Injectable Chemotherapy

\section{APPENDIX A HCPCS/CPT-4 Codes of MM-Specific Anticancer Agents Analyzed}

Medication

HCPCS/Procedure Codes (Route of Administration)

Cyclophosphamide

Melphalan

Vincristine sulfate

Doxorubicin hydrochloride J8600 (Oral), J9245 (Injectable)

Liposomal doxorubicin

J9370 (Injectable), J9375 (Injectable), J9380 (Injectable)

Interferon alfa-2b

Bortezomib

Carfilzomib

J9000 (Injectable), J9001 (Injectable)

Bendamustine

Dexamethasone

Prednisone

J9002 (Injectable)

J9214 (Injectable), S0146 (Injectable), S0148 (Injectable)

J904l (Injectable)

J9047 (Injectable)

J9033 (Injectable)

J1094 (Injectable), J1095 (Injectable), J1100 (Injectable), J8540 (Oral), S0173 (Oral)

J7506 (Oral)

CPT-4=Current Procedural Terminology, 4th Edition; HCPCS = Healthcare Common Procedure Coding System; MM = multiple myeloma. 


\section{Costs Associated with Productivity Loss Among U.S. Patients Newly Diagnosed with Multiple Myeloma Receiving Oral Versus Injectable Chemotherapy}

\section{APPENDIX B NDC Numbers for MM-Specific Anticancer Agents Analyzed}

\begin{tabular}{|c|c|c|}
\hline Medication & $\begin{array}{l}\text { Route of } \\
\text { Administration }\end{array}$ & NDC Number \\
\hline Bendamustine & Injectable & $63459039120,63459039008,63459034804,63459039602,63459039502$ \\
\hline \multirow[t]{2}{*}{ Cyclophosphamide } & Injectable & $\begin{array}{l}10019094510,10019095701,00015050541,00781324494,10019093601,10019093650,10019093901, \\
10019094401,10019094450,10019095601,10019095616,00015050641,00781325594,10019093701, \\
10019093710,10019094201,10019094501,10019094510,10019095701,10019095711,00015050241, \\
00781323394,10019093501,10019093525,10019093801,10019094301,10019094325,10019095501, \\
10019095550,00013563601,00013563670,00015054812,00015054841,00013560601,00013560693, \\
00015053941,00013564601,00013564670,00015054912,00015054941,00013561601,00013561693, \\
00015054641,00013562601,00013562693,00015054712,00015054741\end{array}$ \\
\hline & Oral & $\begin{array}{l}00015050401,00054412925,00054808925,54569571200,54868521800,54868521801,54868521802, \\
00015050301,00015050302,00054413025,00054813025,54569571300,54868500500,54868500501, \\
00054038225,00054038325\end{array}$ \\
\hline \multirow[t]{2}{*}{ Melphalan } & Oral & $\begin{array}{l}00173004535,52609000105,54868433900,54868433901,54868433902,54868433903,54868433904, \\
59572030250\end{array}$ \\
\hline & Injectable & $00173013093,52609300100,59572030101,67457019501,67457021501,67457057901,68152010900$ \\
\hline Daratumumab & Injectable & 57894050205,57894050220 \\
\hline Elotuzumab & Injectable & 00003229111,00003452211 \\
\hline Pomalidomide & Oral & $\begin{array}{l}59572050100,59572050121,59572050200,59572050221,59572050300,59572050321,59572050400, \\
59572050421\end{array}$ \\
\hline $\begin{array}{l}\text { Doxorubicin } \\
\text { hydrochloride }\end{array}$ & Injectable & $\begin{array}{l}00013108691,00069017001,10019092001,53905081010,55390023110,55390024110,67457047810, \\
00015335322,00013111601,00013111683,00013109601,00013109691,53905081110,55390023210 \\
55390024210.00013110601,00013110679,00015335222,00069017101,10019092102,55390023301, \\
55390024301,67457043650,00013113601,00013114601,00013116601,00013117601,00013117687, \\
00013123691,00013124691,00013125679,00013126683,00013128683,00069303020,00069303120, \\
00069303220,00069303320,00069303420,00069400405,00069401510,00069402625, \\
00069403001,00069403101,00069403201,00069403301,00069403401,00069403701,00703504001, \\
00703504301,00703504303,00703504601,25021020705,25021020725,25021020751,45963073355, \\
45963073357,45963073360,45963073368,53150031410,53150031501,53150031701,53150032010, \\
53905081310,53905081410,53905081501,53905081601,55390023510,55390023610,55390023701, \\
55390023801,55390024510,55390024610,55390024701,55390024801,62756082640,62756082740, \\
63323010161,63323088305,63323088310,63323088330,67457039300,67457039354,67457039400, \\
67457039410,67457039525,67457039610,17314960001,17314960002,47335004940,47335005040, \\
47335008250,47335008350,59676096001,59676096002\end{array}$ \\
\hline Bortezomib & Injectable & 63020004901 \\
\hline Carfilzomib & Injectable & 76075010101 \\
\hline Ixazomib citrate & Oral & $63020007801,63020007802,63020007901,63020007902,63020008001,63020008002$ \\
\hline $\begin{array}{l}\text { Panobinostat } \\
\text { lactate }\end{array}$ & Oral & $00078065006,00078065106,00078065206$ \\
\hline Vorinostat & Oral & 00006056840 \\
\hline Interferon alfa-2b & Injectable & $\begin{array}{l}00085057102,00085435001,00085111001,00085435101,00085028502,00085064705,54868308501, \\
00085012002,00085053901,00085435201,54868334100,00085113301,00085117901,00085116801, \\
00085118401,00085125401,00085117902,00085124201,00085118402,00085119102,00085123501\end{array}$ \\
\hline Vincristine sulfate & Injectable & $\begin{array}{l}00013745601,00013745686,00013746686,00703440211,00703441211,61703030906,61703030916, \\
61703030925,61703030926,20536032201\end{array}$ \\
\hline Lenalidomide & Oral & $\begin{array}{l}59572041000,59572041028,59572041030,59572041500,59572041521,59572042000,59572042021, \\
59572042500,59572042521,59572042525,59572040500,59572040528,59572040530,59572040200, \\
59572040228\end{array}$ \\
\hline Thalidomide & Oral & $\begin{array}{l}59572021015,59572021095,59572021513,59572021593,59572022016,59572022096,59572010512, \\
59572010513,59572010592,59572010593,59572020514,59572020517,59572020594,59572020597\end{array}$ \\
\hline
\end{tabular}


APPENDIX B NDC Numbers for MM-Specific Anticancer Agents Analyzed (continued)

\begin{tabular}{|c|c|c|}
\hline Medication & $\begin{array}{c}\text { Route of } \\
\text { Administration }\end{array}$ & NDC Number \\
\hline \multirow[t]{2}{*}{ Dexamethasone } & Oral & $\begin{array}{l}00054317644,00472097208,00472097233,00603114556,00603114756,00677060142,00904097209, \\
54569103400,54879000308,55045142801,55289041004,60346097731,60432046600,60432046608, \\
64679081008,64980050924,68850000108,00054317757,00054317763,00054817716,63629269601, \\
49884008301,49884008310,00006004168,00054417925,00054817925,49884008401,49884008410, \\
51655021277,54868092700,55045266502,58016029000,58016029002,58016029003,58016029012, \\
58016029015,58016029020,58016029030,58016029073,58016029089,00006006368,00054418025, \\
00054818025,00247062407,00247062412,00247062420,00247062421,00247101004,00247101012, \\
21695029030,23490540401,33261055830,33261055860,33261055890,49884008501,49884008510, \\
52959039201,52959039212,52959039221,52959039228,52959039230,54569032200,54569032203, \\
54569032205,54868091600,55045130804,55045130805,55289090310,55289090312,55289090320, \\
58016029300,58016029312,58016029315,58016029320,58016029330,60346055012,60346055015, \\
60346055030,60713002810,60713002815,63629412901,63874044401,63874044412,63874044415, \\
63874044420,63874044421,63874044430,66267006612,66267006630,66336055012,66336055021, \\
68115009612,68115009614,68387017221,00006006312,00254266706,00603319111,52959150421, \\
54569311000,60904008527,00054418125,00054817425,21695072812,35356035930,00054418225, \\
00054818125,00603319221,00904024560,49884008601,49884008610,54868174400,55700026321, \\
55700026355,61919026921,61919026955,63629412701,68115043510,00095008635,00095008651, \\
44183050735,44183050851,44183050921,00054418325,00054817625,21695074510,21695074512, \\
43063026607,54569033601,54569033603,54868315700,54868315701,62682500002,63874047104, \\
63874047105,63874047110,00006009750,00054418425,00054817525,00677084901,10544021206, \\
16590026906,16590026910,16590026960,16590026972,21695038204,21695038206,21695038208, \\
21695038220,21695038260,23490540701,23490540702,33261062502,33261062530,33261062560, \\
33261062590,47463020230,49884008701,49884008703,49884008710,49999005906,49999005930, \\
52959054704,52959054710,52959054711,52959054712,52959054716,52959054720,52959054730, \\
52959054750,54569032402,54569032404,54569032406,54569032407,54569032409,54569572900, \\
54868021800,54868021801,54868021802,54868021803,54868021804,54868021805,54868021806,\end{array}$ \\
\hline & Injectable & $\begin{array}{l}54569395300,62295305807,00314089775,00551011005,54569142300,54868397700,62295305907, \\
62295305706,45861013101,63187034801,76420076901,63323050601,63323050616,00551017410, \\
00641036721,00641036725,00703352403,23490541401,68258896202,00069017701,00069017702, \\
00069454101,00069454102,00703352401,54868609900,63323051610,67457042010,00069019201, \\
00069019202,00069454501,00069454502,00517493025,21695084830,23490541300,23490541301, \\
54569304000,54868087106,55045321203,55150023930,63323016530,67457042100,67457042130, \\
00069017801,00069017802,00069454301,00069454302,00517490525,54569302700,54569302701, \\
54569464800,54569464801,54569464802,54868087100,55150023805,63323016505,63323016526, \\
67457042254,68258897201,68258897202,68258897205,00006762803,00006762825,00069017901, \\
00069017902,00069454701,00069454702,00314089605,00314089610,00314089630,00314089670, \\
00314089675,00517490125,00551003705,00551003730,00703350104,00703351304,49999043425, \\
54569157500,54569472800,55150023701,63323016501,63323016516,66758050122,67457042300, \\
67457042312,76045010610,00006764603,45861013301,76420076601,45861013401,76420081001, \\
45861013201,76420076701\end{array}$ \\
\hline
\end{tabular}

